\title{
Inhaling smoke causes smoke inhalation: put that in your hookah pipe!
}

\author{
Marco L.A. Sivilotti, MD, MSc*; Riyad B. Abu-Laban, MD, MHSc ${ }^{\dagger}$
}

Emergency physicians need no reminders to be vigilant for accidental carbon monoxide poisoning. Because its earliest symptoms are vague and mimic a viral illness, carbon monoxide has been coined "the great masquerader." Missing the diagnosis risks continued exposure in patients discharged back to the same environment and represents a lost opportunity to identify other victims. In this issue, La Fauci and colleagues warn us about an unusual cause of carbon monoxide poisoning: smoking a narghile, commonly known as a water pipe or hookah. ${ }^{1}$ Case reports are valuable not just for cautioning us, as so many do, to "be aware" but also when they identify the leading edge of something big. And hookah smoking is becoming increasingly popular in Canada, with a self-reported past-year prevalence of about one-quarter of young adults in a recent survey. ${ }^{2}$

The history of the hookah dates back some 500 years to South Asia and the Middle East, where its use remains widespread. In recent years, hookah cafés have sprouted up in cities across Canada, and hookah pipes and supplies can be purchased openly in stores or on the Internet. Most Canadian hookah smokers are young urbanites who smoke tobacco or other plant products flavoured with aromatic herbs. Beyond legitimate concerns regarding the chronic health effects of hookah smoking, the case by La Fauci and colleagues highlights the potential for acute, singlesession toxicity from the great masquerader, carbon monoxide.
An important distinction exists between the hookah and other types of smoking. Unlike cigarettes or a pipe, the primary source of combustion in a hookah is charcoal, which is separated from the shisha (tobacco or other plant material being smoked) by a perforated shield. As a result, users predominantly inhale smoke from the charcoal itself when they draw from the mouthpiece. In fact, most of the carbon monoxide found in hookah fumes originates from the charcoal rather than the shisha. From the perspective of carbon monoxide exposure, it is irrelevant whether the shisha contains tobacco, cannabis, aromatic herbs, or even pine needles. In this respect, smoking a hookah is much like breathing the smoke from a smoldering coal fire. Although the water trap cools and humidifies the smoke, it does not filter out carbon monoxide, which is poorly soluble in water. Cooling and humidifying the smoke can in fact increase the dose of carbon monoxide inhaled by allowing users to take much longer draws and to tolerate longer smoking sessions3 hours in this case report. ${ }^{3}$ The flavouring or aromatic herbs added to many types of shisha may also contribute to an illusion that the smoke is nontoxic or even beneficial and may increase the hookah's appeal in young or inexperienced smokers. ${ }^{4}$

The carbon monoxide concentration found in hookah fumes varies but increases under conditions of incomplete combustion, such as could occur with a poorly applied windshield or a suboptimal configuration of the smoldering charcoal. ${ }^{5}$ Even under optimal

From the *Department of Emergency Medicine, Queen's University, Kingston, ON, and †Department of Emergency Medicine, University of British Columbia, Vancouver, BC.

Correspondence to: Dr. Marco L.A. Sivilotti, Department of Emergency Medicine, Queen's University, 76 Stuart Street, Kingston, ON K7L 2V7; marco.sivilotti@queensu.ca.

Submitted October 18, 2011; Accepted October 28, 2011.

This article has been peer reviewed.

(c) Canadian Association of Emergency Physicians

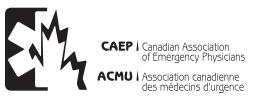


conditions, it far exceeds the carbon monoxide in the exhaust of the 2000 Toyota 4-Runner truck one of us drives. In the blood, measured carboxyhemoglobin levels are much higher in hookah smokers than in cigarette smokers. ${ }^{6}$ In one human volunteer study, carboxyhemoglobin levels exceeded $20 \%$ after 30 minutes in 3 of 45 subjects "instructed to smoke at their own regular pace and pattern."” In another study performed in a hookah café, patrons inhaled on average $130 \pm 21 \mathrm{~L}$ of smoke containing $150 \pm 26 \mathrm{mg}$ of carbon monoxide in 1 hour. To put this dose of carbon monoxide in perspective, only about $600 \mathrm{mg}$ of carbon monoxide is needed to bind half of all the hemoglobin in an adult. And hookah smokers in the foothills or mountainous areas should consider that even moderate altitude increases the toxicity of carbon monoxide.

Smoking outdoors does not make the hookah safer. The session described by La Fauci and colleagues was on an open beach, not a tiny, smoke-filled room. It is also noteworthy that the patient was a teenage girl. With more young Canadian women smoking the hookah, the potential for carbon monoxide exposure during pregnancy increases. The fetus develops in a low-oxygen environment downstream of the placenta and is exquisitely sensitive to even low levels of carbon monoxide. Moreover, none of the patient's smoking companions presented for assessment-an unfortunate circumstance often seen with carbon monoxide exposure.

Poisoning prevention will be the focus of the March 2012 SafeKids Week, an event that will emphasize public health advocacy, legislation, and education. It is clear that hookah smoking can cause acute carbon monoxide toxicity. Would it not be ironic if our youth are turning to the hookah in part because of the stigma of cigarette smoking? ${ }^{4}$ Given the healthy respect emergency physicians have for carbon monoxide, this case by La Fauci and colleagues raises several important questions regarding injury prevention. Should the Canadian emergency medicine community enter the debate on the legality of hookah cafés? To date, this debate has largely centred on the applicability of municipal bylaws and the chronic toxicity of tobacco smoke. ${ }^{8}$ Should we join the call for extending smoking bans to public parks and outdoor spaces, meant to further denormalize smoking in the eyes of impressionable children?" Should we expect Health Canada to consider banning the hookah based on the Canada Consumer Product Safety Act, new legislation intended to protect the public from products that are dangerous to health when used as intended? Or should we simply content ourselves by educating our patients and colleagues to "be aware" of what seems obvious: that inhaling smoke, or burning charcoal indoors for that matter, can be a bad idea? Neither traditional practices nor popular youth trends should be immune from scrutiny and common sense.

Competing interests: At least one of the authors reports having smoked tobacco from the narghile during his travels and at his wedding; however, he received no compensation and frequently developed a headache related to this exposure.

Keywords: carbon monoxide, hookah, narghile, smoking, water pipe

\section{REFERENCES}

1. La Fauci G, Weiser G, Steiner IP, Shavit I. Carbon monoxide poisoning in narghile (water pipe) tobacco smokers. CFEM 2012;15:00-00.

2. Dugas E, Tremblay ML, Low NCP, et al. Water-pipe smoking among North American youths. Pediatrics 2010;125: 1184-9, doi:10.1542/peds.2009-2335.

3. Cobb CO, Shihadeh A, Weaver MF, Eissenberg T. Waterpipe tobacco smoking and cigarette smoking: a direct comparison of toxicant exposure and subjective effects. Nicotine Tob Res 2011;13:78-87, doi:10.1093/ntr/ntq212.

4. Roskin J, Aveyard P. Canadian and English students' beliefs about waterpipe smoking: a qualitative study. BMC Public Health 2009;9:10, doi:10.1186/1471-2458-9-10.

5. Sajid KM, Akhter M, Malik GQ. Carbon monoxide fractions in cigarette and hookah (hubble bubble) smoke. 7 Pak Med Assoc 1993;43:179-82.

6. Zahran FM, Ardawi MS, Al Fayez SF. Carboxyhemoglobin concentrations in smokers of sheesha and cigarettes in Saudi Arabia. Br Med 7 (Clin Res Ed) 1985;291:1768-70, doi:10.1136/ bmj.291.6511.1768-a.

7. Hakim FM, Hellou EB, Goldbart AM, et al. The acute effects of water-pipe smoking on the cardiorespiratory system. Chest 2011;139:775-81.

8. CBC Radio. Q. Should hookah be exempt from anti-smoking rules? Available at: http://www.cbc.ca/q/blog/2011/09/06/ should-hookah-be-exempt-from-anti-smoking-rules/ (accessed October 15, 2011).

9. Colgrove J, Bayer R, Bachynski KE. Nowhere left to hide? The banishment of smoking from public spaces. N Engl 7 Med 2011;364:2375-7, doi:10.1056/NEJMp1104637. 